OPEN ACCESS

Edited by:

Etienne Challet,

Université de Strasbourg, France

Reviewed by:

Henrik Oster

University of Lübeck, Germany

Shihoko Kojima,

Virginia Tech, United States

${ }^{*}$ Correspondence:

Martin Fredensborg Rath

mrath@sund.ku.dk

Specialty section:

This article was submitted to

Chronobiology,

a section of the journal

Frontiers in Physiology

Received: 07 May 2021 Accepted: 06 October 2021 Published: 27 October 2021

Citation:

Bering T, Hertz H and Rath MF (2021) The Circadian Oscillator of the Cerebellum: Triiodothyronine Regulates Clock Gene Expression in Granule Cells in vitro and in the Cerebellum of Neonatal Rats in vivo.

Front. Physiol. 12:706433. doi: 10.3389/fphys.2021.706433

\section{The Circadian Oscillator of the Cerebellum: Triiodothyronine Regulates Clock Gene Expression in Granule Cells in vitro and in the Cerebellum of Neonatal Rats in vivo}

\author{
Tenna Bering, Henrik Hertz and Martin Fredensborg Rath* \\ Department of Neuroscience, Faculty of Health and Medical Sciences, University of Copenhagen, Copenhagen, Denmark
}

The central circadian clock resides in the suprachiasmatic nucleus (SCN) of the hypothalamus, but an SCN-dependent molecular circadian oscillator is present in the cerebellar cortex. Recent findings suggest that circadian release of corticosterone is capable of driving the circadian oscillator of the rat cerebellum. To determine if additional neuroendocrine signals act to shape cerebellar clock gene expression, we here tested the role of the thyroid hormone triiodothyronine (T3) in regulation of the cerebellar circadian oscillator. In cultured cerebellar granule cells from mixed-gender neonatal rats, T3 treatment affected transcript levels of the clock genes Per2, Arntl, Nr1d1, and Dbp, suggesting that T3 acts directly on granule cells to control the circadian oscillator. We then used two different in vivo protocols to test the role of T3 in adult female rats: Firstly, a single injection of T3 did not influence clock gene expression in the cerebellum. Secondly, we established a surgical rat model combining SCN lesion with a programmable micropump infusing circadian physiological levels of T3; however, rhythmic infusion of T3 did not reestablish differential clock gene expression between day and night in SCN lesioned rats. To test if the effects of T3 observed in vitro were related to the developmental stage, acute injections of T3 were performed in mixedgender neonatal rats in vivo; this procedure significantly affected cerebellar expression of the clock genes Per1, Per2, Nr1d1, and Dbp. Developmental comparisons showed rhythmic expression of all clock genes analyzed in the cerebellum of adult rats only, whereas T3 responsiveness was limited to neonatal animals. Thus, T3 shapes cerebellar clock gene profiles in early postnatal stages, but it does not represent a systemic circadian regulatory mechanism linking the SCN to the cerebellum throughout life.

Keywords: thyroid hormone, T3, cerebellum, clock gene, circadian, suprachiasmatic nucleus, iPRECIO programmable micropump

\footnotetext{
Abbreviations: Arntl, aryl hydrocarbon receptor nuclear translocator-like protein 1 (also known as Bmal1); Clock, circadian locomotor output cycles kaput; Dbp, D-box binding PAR bZIP transcription factor; Gapdh, glyceraldehyde-3-phosphate dehydrogenase; $\mathrm{Hr}$, hairless; IP, intraperitoneally; Nr1d1, nuclear receptor subfamily 1 group D member 1 (also known as Rev-Erb $\alpha$ ); Per1, period 1; Per2, period 2; qRT-PCR; quantitative reverse-transcription real-time PCR; RRID, research resource identifier; SCN, suprachiasmatic nucleus; Sham-veh, sham SCN-lesioned rats with vehicle in the pump; SCNx-T3, SCN-lesioned rats with T3 in the pump, SCNx-veh SCN-lesioned rats with vehicle in the pump; T3, triiodothyronine; T4, thyroxine; Thra, thyroid hormone receptor alpha; ZT, Zeitgeber time (hours after lights on).
} 


\section{INTRODUCTION}

Basic physiology includes a number of $24 \mathrm{~h}$ circadian biological rhythms, including rhythmic secretion of hormones (Kalsbeek and Fliers, 2013; Challet, 2015). The circadian control in mammals emanates from the suprachiasmatic nucleus (SCN) of the hypothalamus, in which each neuron contains a molecular clock of transcriptional autoregulatory loops involving clock genes and clock gene products (Reppert and Weaver, 2002). This molecular clockwork exists in numerous tissues as socalled peripheral oscillators controlled by the master clock of the SCN (Balsalobre et al., 1998; Ko and Takahashi, 2006). In the cerebellum, rhythms of clock gene transcription are detectable in neurons of the cerebellar cortex and display a 6 h delay as compared to the SCN (Mendoza et al., 2010; Rath et al., 2012, 2014; Bering et al., 2017). Lesion studies show that an input from the SCN is a prerequisite for rhythmic clock gene expression in the cerebellum (Rath et al., 2012), and although many areas of the brain receive neural connections from the SCN, neither anterograde nor retrograde tracing studies have established a direct neural pathway between the SCN and the cerebellum (Vrang et al., 1995, 1997). In this regard, we have recently shown that rhythmic administration of the circadian hormone corticosterone can reintroduce a rhythm in rat cerebellar clock gene expression otherwise abolished by SCN ablation (Bering et al., 2020). However, in adrenalectomized rats devoid of corticosterone, local cerebellar oscillations in clock genes are still detectable, indicating that additional factors act to shape circadian signaling to the cerebellum (Bering et al., 2020). In the present study, we aim to determine whether thyroid hormone provides a signal to control clock gene expression in the cerebellum.

The interplay between thyroid hormones and the brain is evident from studies reporting crucial roles for thyroid hormones both during brain development (Legrand, 1979; Chatonnet et al., 2011) and in maintaining normal brain functions in adulthood (Smith et al., 2002; Remaud et al., 2014). The release of thyroid hormones is controlled through the hypothalamic-pituitary-thyroid axis; various degrees of circadian rhythmicity in this system have been previously reported. In the rat, low amplitude daily rhythms in serum triiodothyronine (T3) with the acrophase within the animal's rest phase, e.g., peaking levels during the light phase, have been described (Jordan et al., 1980; Campos-Barros et al., 1997; Kalsbeek et al., 2000; Fahrenkrug et al., 2017). However, other studies have not been able to detect a circadian rhythm in T3 in rat serum (Soutto et al., 1998). The overall picture of circadian biology of T3 is further complicated by marked intra- and inter-individual variations in $\mathrm{T} 3$ serum concentrations obtained in studies based on blood sampling for several consecutive days (Rookh et al., 1979), as well as pronounced gender-specific differences (Kalsbeek et al., 2000). Most importantly in the context of the current study, the presence of thyroid receptors is well-documented in the rat cerebellum (Bradley et al., 1992).

With the aim of determining the possible role of thyroid hormone in regulation of the circadian oscillator of the cerebellum, we here employed both in vitro and surgical in vivo models combined with analyses of circadian clock gene expression in cerebellar neurons.

\section{MATERIALS AND METHODS}

\section{Animals}

Female Sprague Dawley rats were obtained from Janvier Labs (Saint Berthevin Cedex, France; RRID:RGD_70508) and kept under a $12 \mathrm{~h}$ light/12 h dark schedule with food and water ad libitum. Neonatal rats (mixed gender) used in this study were 7-8 days of age and obtained from single housed pregnant mothers. All experiments on adult rats were performed on females (120-200 g at arrival), which were allowed to acclimatize for 1-2 weeks. Adult animals were housed in pairs, but single housed post-surgery. All adult animals were 8 weeks of age at the end of their experimental protocols. Surgeries were performed under sevoflurane-anesthesia to ensure fast recovery; for analgesia, the animals received carprofen, bupivacaine and buprenorphine (Bering et al., 2020); buprenorphine was administered as a single preoperative dose. Animals were killed by decapitation. All animal experiments were performed in accordance with the guidelines of EU directive 2010/63/EU. The specific experiments included in this study were approved by the Danish Council for Animal Experiments (authorization number 2017-15-0201-01190) and by The Faculty of Health and Medical Sciences at University of Copenhagen (authorization numbers P17-311 and P19-118).

\section{Thyroid Hormone}

T3 (Sigma Aldrich; catalog number T6397) was dissolved in $0.05 \mathrm{~N} \mathrm{NaOH}(1 \mathrm{mg} \mathrm{T} 3 / 1 \mathrm{ml} \mathrm{NaOH})$ with aliquots stored at $-20^{\circ} \mathrm{C}$. For each experiment, T3 aliquots were diluted in PBS. Vehicle in vivo groups received matching concentrations of $\mathrm{NaOH}$ dissolved in PBS.

\section{Experiments on Cerebellar Granule Cell Cultures}

Rat pups were euthanized by decapitation, cerebella were dissected and primary granule cell cultures were prepared as previously described (Ilieva et al., 2019). Cells were plated in 6well poly-l-lysine coated plates with 500,000 cells in $2 \mathrm{ml}$ media per well. On day 2, 50\% of the media was replaced. On day 3, the cells received either $5 \mu \mathrm{l} 40 \mu \mathrm{M}$ T3 dissolved in $\mathrm{H}_{2} \mathrm{O}$ for a final concentration of $100 \mathrm{nM}$ or $5 \mu \mathrm{l} \mathrm{H} \mathrm{H}_{2} \mathrm{O}$ (control). Cells were harvested after $12 \mathrm{~h}$. T3 concentration and duration of stimulation were chosen to match conditions known to affect circadian gene expression in vitro (Kim et al., 2010). Cells were frozen on dry ice for quantitative reverse-transcription real-time PCR (qRT-PCR).

\section{Triiodothyronine Delivery in vivo by Single Injection}

For single injections of T3 in adult rats, female rats $(n=9$; 230-257 g) received $1 \mathrm{ml}$ of $25 \mu \mathrm{g} / \mathrm{ml} \mathrm{T3}$ intraperitoneally 
(IP) (97-109 $\mu \mathrm{g} \mathrm{T} 3 / \mathrm{kg})$. A control group $(n=10 ; 230-$ $261 \mathrm{~g})$ received $1 \mathrm{ml}$ of vehicle IP. Injections were given at Zeitgeber time (ZT) 5 and animals were euthanized at ZT9 in $\mathrm{CO}_{2}$ anesthesia followed by decapitation. Brains were removed and the right cerebellar hemisphere was dissected and frozen on dry ice for qRT-PCR. For single injections of T3 in neonatal rats, pups $(10-13 \mathrm{~g})$ received $100-130 \mu \mathrm{l} 10 \mu \mathrm{g} / \mathrm{ml}$ T3 IP (100 $\mu \mathrm{g}$ T3/kg) on postnatal day 7 at ZT5 followed by decapitation at ZT9 or ZT17, respectively. T3 dosage and duration of stimulation were chosen to match conditions known to affect circadian gene expression in vivo (Klitten et al., 2008). Also, injection of T3 was chosen instead of thyroxine (T4) to avoid having endogenous deiodinase activity as a limiting and complicating factor, since only half of the endogenous T3 in the cerebellum is converted from T4 locally (Crantz et al., 1982). For each time point, T3-injected pups $(n=6-7)$ were compared to vehicle-injected controls $(n=5-6)$ from the same litter. The cerebellum was removed and frozen on dry ice for qRT-PCR.

\section{Suprachiasmatic Nucleus Lesion and Triiodothyronine Delivery in vivo by Repetitive Circadian Oscillating Infusion}

Lesions of the SCN were combined with exogenous rhythmic administration of $\mathrm{T} 3$ by use of programmable micropumps mimicking circadian oscillations of T3 within a dose range determined by previous studies of the physiological circadian rhythm in female rats (Jordan et al., 1980; Kalsbeek et al., 2000; Fahrenkrug et al., 2017). The experimental setup consisted of three combinations of SCN lesion and pump content: Sham SCN lesioned rats with vehicle in the pump (Sham-veh), SCN lesioned rats with vehicle in the pump (SCNx-veh), and SCN lesioned rats with T3 in the pump (SCNx-T3).

Surgeries were performed as previously described (Bering et al., 2020). In short, the SCN was ablated bilaterally with a stereotaxic electrical lesion. A telemetry transmitter (TA-F10 from Data Sciences International) was positioned subcutaneously in the midline of the back just caudal to the scapulae. Actograms of locomotor activity and body temperature were generated from a 6-day period just prior to euthanasia using ActogramJ (Schmid et al., 2011; Figure 1A). Sampling frequency was set to obtain data for $10 \mathrm{~s}$ every $10 \mathrm{~min}$. Chi-square periodograms were used to analyze potential circadian rhythms with a predefined period of $1440 \mathrm{~min}$; rhythm robustness (Qp) was calculated as a relative index for stationarity of oscillations (Refinetti, 2004). SCN lesion was verified by a loss of rhythmicity in both circadian locomotion and body temperature analyses and evaluation of Nissl-stained histological sections spanning the supraoptic area.

During the same surgery session, animals were also implanted with a programmable iPRECIO SMP-200 pump (Alzet, Tokyo, Japan) positioned subcutaneously in the midline of the back just caudal to the scapulae. Previous literature has reported that an exogenous administration of $3 \mu \mathrm{g} / \mathrm{kg}$ body weight $\mathrm{T} 3$ in thyroidectomized rats result in euthyroid T3 serum levels

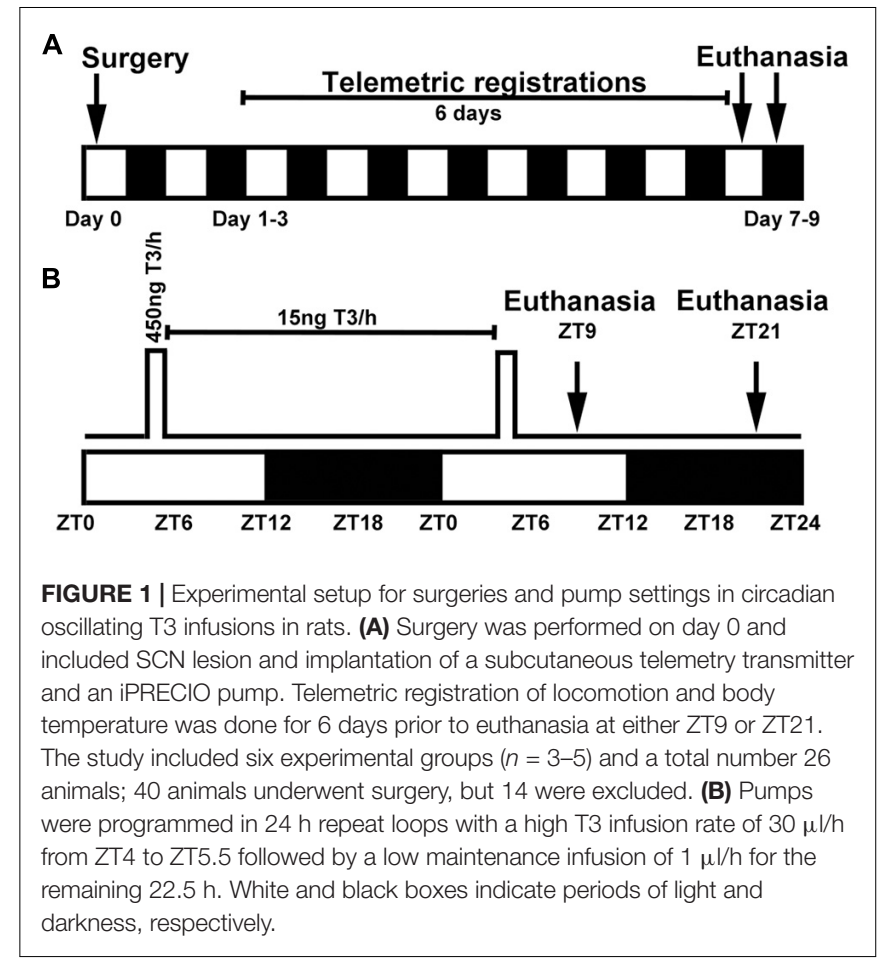

(Giannocco et al., 2004). All pumps were programmed to deliver repeated $24 \mathrm{~h}$ cycles of a high infusion rate of 30 $\mu \mathrm{l} / \mathrm{h}$ from ZT4 to ZT5.5 followed by a low infusion rate of $1 \mu \mathrm{l} / \mathrm{h}$ the additional $22.5 \mathrm{~h}$ to avoid clotting of the tube outlet (Figure 1B). This timely profile was chosen to mimic the previously reported increase in serum T3 early in the light period (Jordan et al., 1980; Campos-Barros et al., 1997; Kalsbeek et al., 2000; Fahrenkrug et al., 2017) with a T3 half-life of 7 $\mathrm{h}$ (Angley et al., 1996) in the rat. The pump reservoir was prefilled with $900 \mu \mathrm{l}$ of $15 \mathrm{ng} / \mu \mathrm{l} \mathrm{T3}$ or vehicle. Considering an individual weight variation of the rats and a prefixed T3 infusion protocol, the T3 delivery in high dose infusion was 2.8-3.6 $\mu \mathrm{g} / \mathrm{kg} / 1.5 \mathrm{~h}$, the T3 maintenance dose range was 1.4$1.8 \mu \mathrm{g} / \mathrm{kg} / 22.5 \mathrm{~h}$; in all resulting in a total daily $\mathrm{T} 3$ dose of $4.2-5.4 \mu \mathrm{g} / \mathrm{kg}$.

At the end of the experimental protocol (Figure 1), the rats were deeply anesthetized with $\mathrm{CO}_{2}$. From the time the rats were removed from the animal housing facility, an intracardial blood sample was collected within $3 \mathrm{~min}$; animals were euthanized immediately after blood samples by decapitation at ZT9 and ZT21, respectively. Anesthesia at ZT21 was performed in dim red light. Each brain was extirpated and divided with a sagittal section $2 \mathrm{~mm}$ to the right of the midline. The left half of the brain including the bilateral structure of the SCN (for confirmation of SCN lesion and in situ hybridization) and the cerebellum dissected from the right half (for qRT-PCR) were frozen on crushed dry ice and stored at $-80^{\circ} \mathrm{C}$. Blood samples were placed at room temperature to clot for $30 \mathrm{~min}$ then centrifuged at $1,000 \mathrm{~g}$ for $10 \mathrm{~min}$ at $4^{\circ} \mathrm{C}$ for serum separation. Serum was stored at $-80^{\circ} \mathrm{C}$. Serum samples were analyzed on a Cobas 8000 (Roche Diagnostics) by Department 
of Clinical Biochemistry, Bispebjerg Hospital, Copenhagen, Denmark (Fahrenkrug et al., 2017).

\section{Quantitative Reverse-Transcription Real-Time PCR}

RNA was extracted by use of TrizOL (Life Technologies) and $1 \mu \mathrm{g}$ of extracted RNA was subjected to DNase I treatment (Thermo Fisher Scientific). cDNA synthesis from 500 ng of DNase treated RNA was performed using SuperScript III (Thermo-Fisher Scientific). All protocol steps were done according to manufacturer's protocols. Real-time amplification was performed in a LightCycler 96 (Roche) with the program: $95^{\circ} \mathrm{C}$ for $10 \mathrm{~min} ; 40$ cycles of $95^{\circ} \mathrm{C}$ for $10 \mathrm{~s}, 63^{\circ} \mathrm{C}$ for 10 $\mathrm{s}, 72^{\circ} \mathrm{C}$ for $15 \mathrm{~s}$. Reaction volumes of $10 \mu \mathrm{l}$ included 0.2 $\mu \mathrm{l}$ of cDNA in a master mix consisting of $0.5 \mu \mathrm{M}$ primer, Faststart Essential DNA Green Master (Roche) and molecular grade water. For sequences of primers used for amplification (see Table 1). Internal standard curves were generated from sequenced plasmids containing the target PCR product (Rath et al., 2013; Bering et al., 2020) in 10-fold dilutions in each run. Specificity was confirmed by melting curve analysis and gel electrophoresis. Transcript levels were normalized against those of glyceraldehyde-3-phosphate dehydrogenase (Gapdh).

\section{In situ Hybridization}

Radiochemical in situ hybridization was performed on coronal $12 \mu \mathrm{m}$ cryosections of the cerebellum. DNA probes were labeled with ${ }^{35}$ S-dATP (Perkin Elmer) and separate sections were hybridized for each gene as previously described (Klitten et al., 2008). Probe sequences for detection of period 2 (Per2) and nuclear receptor subfamily 1 group D member 1 (Nr1d1) transcripts have been previously published (Rath et al., 2012). Hybridized sections were exposed to an X-ray film and the autoradiographical images were digitized and quantified using Scion Image Beta 4.0.2 (Scion). Optical densities of the hybridization signal were converted to $\mathrm{dpm} / \mathrm{mg}$ by use of a standard curve of known values of ${ }^{14} \mathrm{C}$ standards co-exposed on every $\mathrm{X}$-ray film. For each animal, 4 tissue sections were measured and averaged. The area of densitometric measurement was confined to the granular layer and Purkinje cells of a dorsal folium of the vermis.

\section{Statistical Analyses and Experimental Design}

Statistical analyses were performed in Prism version 9.2 (GraphPad Software). Student's $t$-test was used to analyze qRTPCR data from in vitro studies (Figure 2) and acute effects of T3 injection in adult rats (Figure 3). F-test was used to assess data distribution; Welch's correction was applied as specified in the figure legends. Two-way ANOVA followed by Bonferroni multiple-comparisons test was used for serum T3 concentrations (Figure 4), gene expression analyses in rhythmically T3 infused rats (Figures 5, 6), acute effects of T3 in neonatal rats (Figure 7) and diurnal analyses of gene expression at different developmental ages (Figure 8). $n$-values are given in figure legends and below. A $p$-value $<0.05$ was considered statistically significant. Data are presented as scatter plots with group mean and SEM.

In this study, $\mathrm{n}$ refers to the number of individual animals or individual cell culture preparations treated as separate samples in each experimental group. In each experiment, animals from all experimental groups were tested in parallel. For blinding purposes, each sample was given a number; the number was not revealed during data acquisition, but only for the following data analysis. No data points were excluded and tests for outliers were not performed. For acute injections in adult animals (Figure 3), each experimental group contained 9-10 animals $(n=9-10)$ with a total number of 19 animals used. For acute injections in neonatal animals (Figure 6), two experiments were performed at different time points; each experiment included two experimental groups of 5-7 animals $(n=5-7)$ from the same litter with a total number of 24 animals used. For diurnal analyses of gene expression at different developmental ages (Figure 8), each experimental group included 3-4 animals $(n=3-4)$ in eight experimental groups with a total of 29 animals used. Our design for the experiment with $\mathrm{SCN}$-lesions and circadian infusion of exogenous hormone (Figures 4-6) included 3-5 animals in six experimental groups $(n=3-5)$ and a total number 26 animals used. This was based on previous experiments on circadian expression of clock genes in the cerebellum $(n=3)$ (Rath et al., 2012) and the effect of SCN-lesions and exogenous hormone on cerebellar clock gene expression $(n=4)$ (Bering et al., 2020). Exclusion criteria based on telemetric and histological analyses are described above. Ten animals were excluded based on these criteria (two sham-veh, four SCNx-veh, four SCNx-T3);

TABLE 1 | Sequences of primers used for qRT-PCR.

\begin{tabular}{lllll}
\hline Transcript & GenBank accession number & Position & Forward primer $\left(\mathbf{5}^{\prime} \mathbf{-} \mathbf{3}^{\prime}\right)$ & Reverse primer $\left(\mathbf{5}^{\prime} \mathbf{-} \mathbf{3}^{\prime}\right)$ \\
\hline Per1 & NM_001034125.1 & $2411-2574$ & acacccagaaggaagagcaa & gcgagaacgctttgctttag \\
Per2 & NM_031678.2 & $3319-3409$ & catctgccacctcagactca & ctggtgtgacttgtatcactgct \\
Arntl & NM_024362.2 & $2038-2132$ & attccagggggaaccaga & gaaggtgatgaccctcttatcct \\
Clock & NM_021856.3 & $2402-2483$ & cagccgcatccttcagtt & catggagcaaccgagatgt \\
Nr1d1 & NM_001113422.2 & $1878-2167$ & gcacgaccaggtgaccctgct & gctgctccaccgaagcggaatt \\
Dbp & NM_012543.3 & $1131-1301$ & gcaaggaaagtccaggtgcccg & ctcctgccgcaatagggcgtt \\
Thra & NM_001017960.2 & $572-739$ & cctggacaaagacgagcagt & atcttgtcgatgacgcagca \\
Hr & NM_024364.3 & $2699-2835$ & tgtagcctgtggtcgcatag & ggctggagacaaactgggtc \\
Gapdh & NM_017008.4 & $77-386$ & tggtgaaggtcggtgtgaacggat & tccatggtggtgaagacgccagta
\end{tabular}



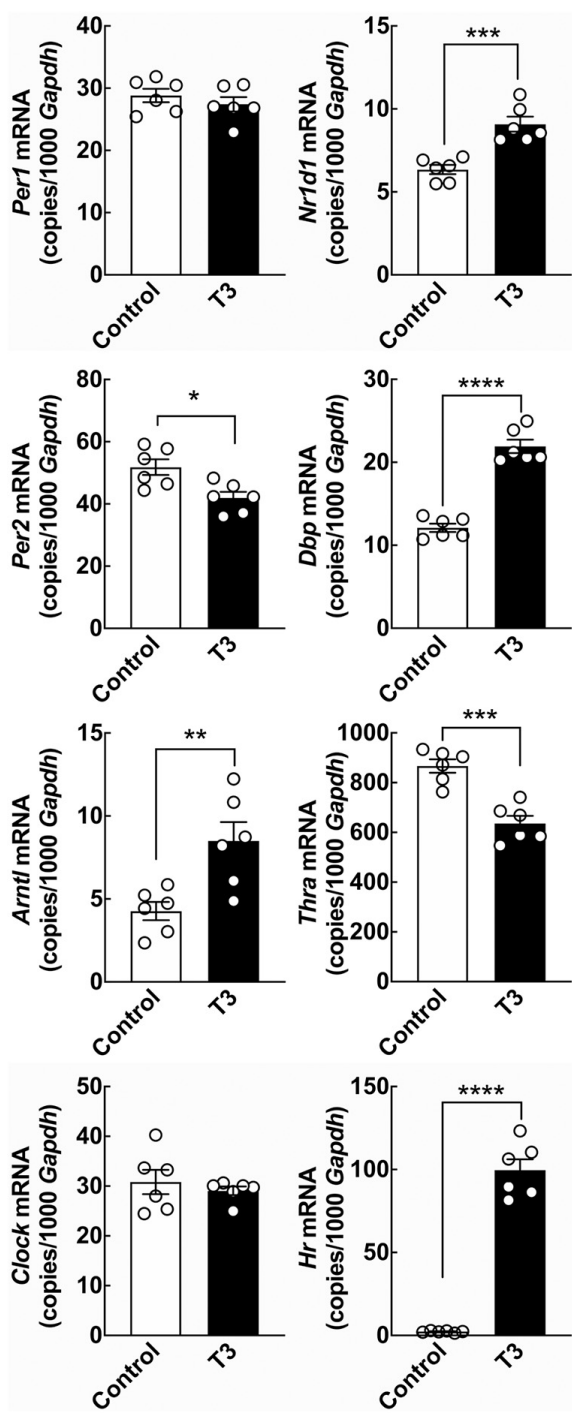

FIGURE 2 | The effect of T3 on clock gene expression in cultured rat cerebellar granule cells determined by qRT-PCR. Cerebellar granule cells were exposed to $0.1 \mu \mathrm{M}$ T3 for $12 \mathrm{~h}$ and compared to untreated controls. Significant effects on expression levels of the clock genes Per2, Arntl, Nr1d1, and $D b p$ were revealed by Student's $t$-test. In addition significant effects on the thyroid hormone receptor Thra and the positive control T3-responsive gene $\mathrm{Hr}$ were detectable. Analyses of Clock and $\mathrm{Hr}$ included Welch's correction. ${ }^{\star} p<0.05 ;{ }^{\star \star} p<0.01 ;{ }^{* \star \star} p<0.001 ;{ }^{\star \star \star \star} p<0.0001 . n=6$.

furthermore, four animals were euthanized post-surgery based on general welfare assessments.

\section{RESULTS}

\section{Triiodothyronine Modulates Clock Gene Expression in Cultured Cerebellar Granule Cells}

To determine if $\mathrm{T} 3$ can act on neurons of the cerebellum to control expression of circadian clock genes, the effect of T3
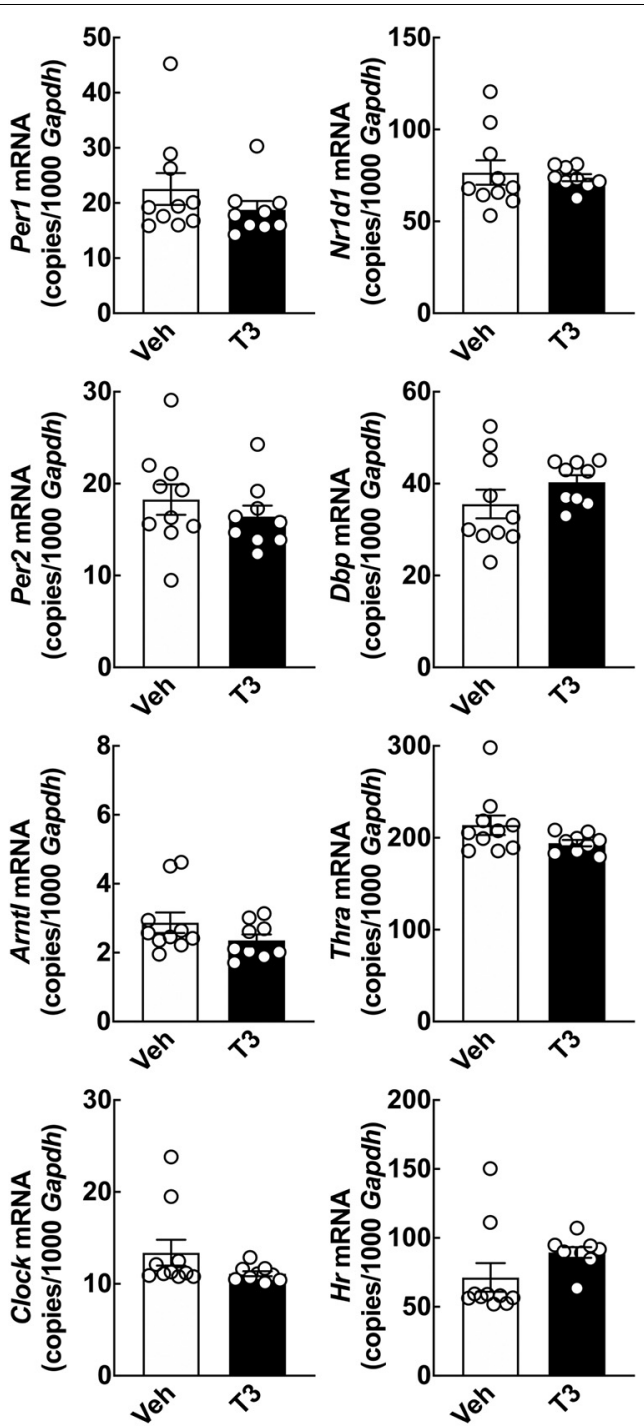

FIGURE 3 | Acute effect of T3 on cerebellar clock gene expression in adult rats determined by qRT-PCR. Adult rats (8 weeks of age) received $0.1 \mathrm{mg} / \mathrm{kg}$ T3 by IP injection at ZT5 and were subsequently euthanized at ZT9. Controls received vehicle (Veh). Student's t-tests did not reveal significant effects in cerebellar clock gene expression between the T3 injected rats and the vehicle group; analyses of Nr1d1 and Dbp included Welch's correction. $n=9-10$.

stimulation on expression of selected clock genes was analyzed in cerebellar granule neurons from neonatal rats in vitro by qRTPCR (Figure 2). Significant reductions in mRNA levels was found for the clock gene Per2 ( $p<0.05$, Student's $t$-test), whereas elevated levels of mRNA were detected for the clock genes aryl hydrocarbon receptor nuclear translocator-like protein 1 (Arntl) ( $p<0.01$, Student's $t$-test), Nr1d1 ( $p<0.001$, Student's $t$-test) and D-box binding PAR bZIP transcription factor $(D b p)(p<0.0001$, Student's $t$-test) as compared to controls. The transcript levels of the clock genes period 1 (Per1) and circadian locomotor output cycles kaput (Clock) were unaffected by exposure to T3. In accord with previous studies in neonatal rat cerebella (Thompson, 1996), 
the T3-responsive gene hairless $(H r)$, here used as a positive control, was upregulated by T3 treatment $(p<0.0001$, Student's $t$-test). In addition, analysis of thyroid hormone receptor alpha (Thra), the major thyroid hormone receptor isoform of the cerebellum (Bradley et al., 1992), revealed a reduction in transcript levels following T3-treatment $(p<0.001$, Student's $t$-test), in agreement with data from other ex vivo model systems (Hernandez-Linares et al., 2019).

\section{Acute in vivo Effects on Clock Gene Expression in the Mature Cerebellum From of a Single Triiodothyronine Injection}

The alterations in clock gene expression induced by T3 in cell cultures prompted us to investigate effects of $\mathrm{T} 3$ in vivo. A single IP injection of a high dose T3 was performed at ZT5 in adult rats, which were subsequently euthanized at ZT9. qRT-PCR analyses of the cerebellum revealed no change in transcript levels of neither clock genes nor Thra and $\mathrm{Hr} 4 \mathrm{~h}$ after T3 injection as compared to controls (Figure 3).

\section{Clock Gene Expression in the Cerebellum of Suprachiasmatic Nucleus Lesioned Rats Implanted With Micropumps Releasing Exogenous Triiodothyronine in a $\mathbf{2 4} \mathrm{h}$ Rhythm}

To determine if a circadian rhythm in serum T3 is sufficient to drive the SCN-dependent rhythm in cerebellar clock gene expression, SCN lesions were combined with rhythmic infusion of T3 by use of a programmable micropump (Figure 1). These procedures and sham controls were combined in three surgically modified experimental groups: Sham-SCN lesioned rats with vehicle in the pump (Sham-veh), SCN lesioned rats with vehicle in the pump (SCNx-veh), and SCN lesioned rats with T3 in the pump (SCNx-T3).

T3 concentrations were determined in serum samples from rats from all experimental groups sacrificed at ZT9 and ZT21, respectively (Figure 4A). SCNx-veh animals did not differ in serum T3 concentrations between the two daily sampling time points, but a highly significant rhythm in serum T3 was detected in SCNx-T3 animals $(p<0.001$, Bonferroni multiple-comparisons test) (Figure 4A). In the sham-veh control group, T3 serum concentrations were not significantly different between ZT9 and ZT21.

Telemetric analyses of locomotor activity and body temperature were included for verification of functional SCN ablation (Figures 4B-D). All controls (Sham-veh) exhibited circadian rhythmicity in locomotor activity with high activity levels during the dark phase, whereas lesioning the SCN (SCNxveh) resulted in activity bursts spread randomly across the 24 $\mathrm{h}$ day (Figure 4B). Rhythmic exogenous administration of T3 did not restore rhythmicity in locomotion in SCN lesioned animals (SCNx-T3) (Figure 4B). Telemetric registrations of body temperature revealed similar results (Figure 4C). Hence, the controls were significantly rhythmic $(p<0.05)$ in both the
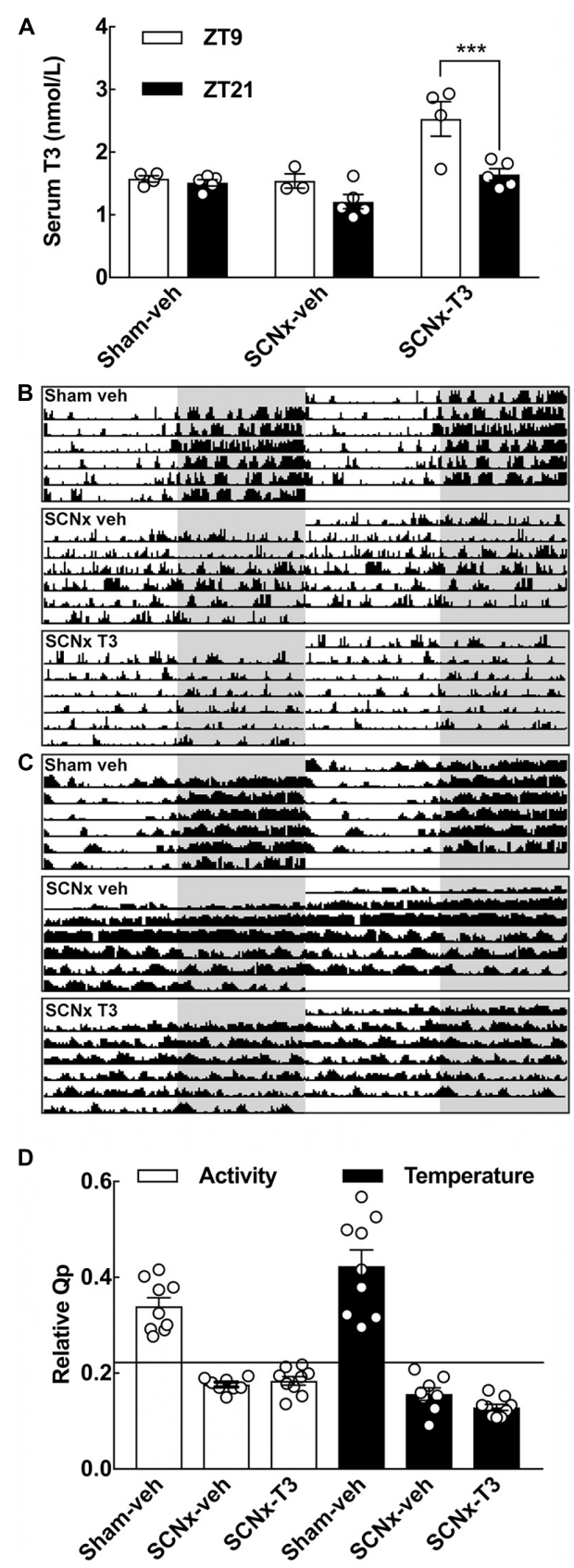

FIGURE 4 | Effects of SCN-lesions and circadian oscillating T3 infusion on T3 serum concentrations, locomotion and body temperature. (A) Serum T3 concentrations determined from the three experimental groups of adult rats (8 weeks of age), sham-veh, SCNx-veh, and SCNx T3 at ZT9 and ZT21, respectively. Data were analyzed by two-way ANOVA followed by Bonferroni multiple-comparisons tests. A significant rhythm in serum T3 is detectable in SCNx-T3. ${ }^{* *} p<0.001 . n=3-5$. (B) Representative double-plotted actograms of locomotor activity from each experimental group. Locomotor activity values within the range $0-25 \mathrm{~cm} / \mathrm{min}$ are displayed. Shaded areas indicate the $12 \mathrm{~h}$ of darkness. (C) Representative double-plotted actograms of body temperature from each experimental group. Temperature values within the range $36-38^{\circ} \mathrm{C}$ are displayed. Shaded areas indicate the $12 \mathrm{~h}$ of darkness. (D) Rhythm robustness on the $y$-axis expressed as a relative $Q p$-value for activity (left) and temperature (right). Horizontal line depicts a significance level of $p=0.05$. $n=8-9$. 

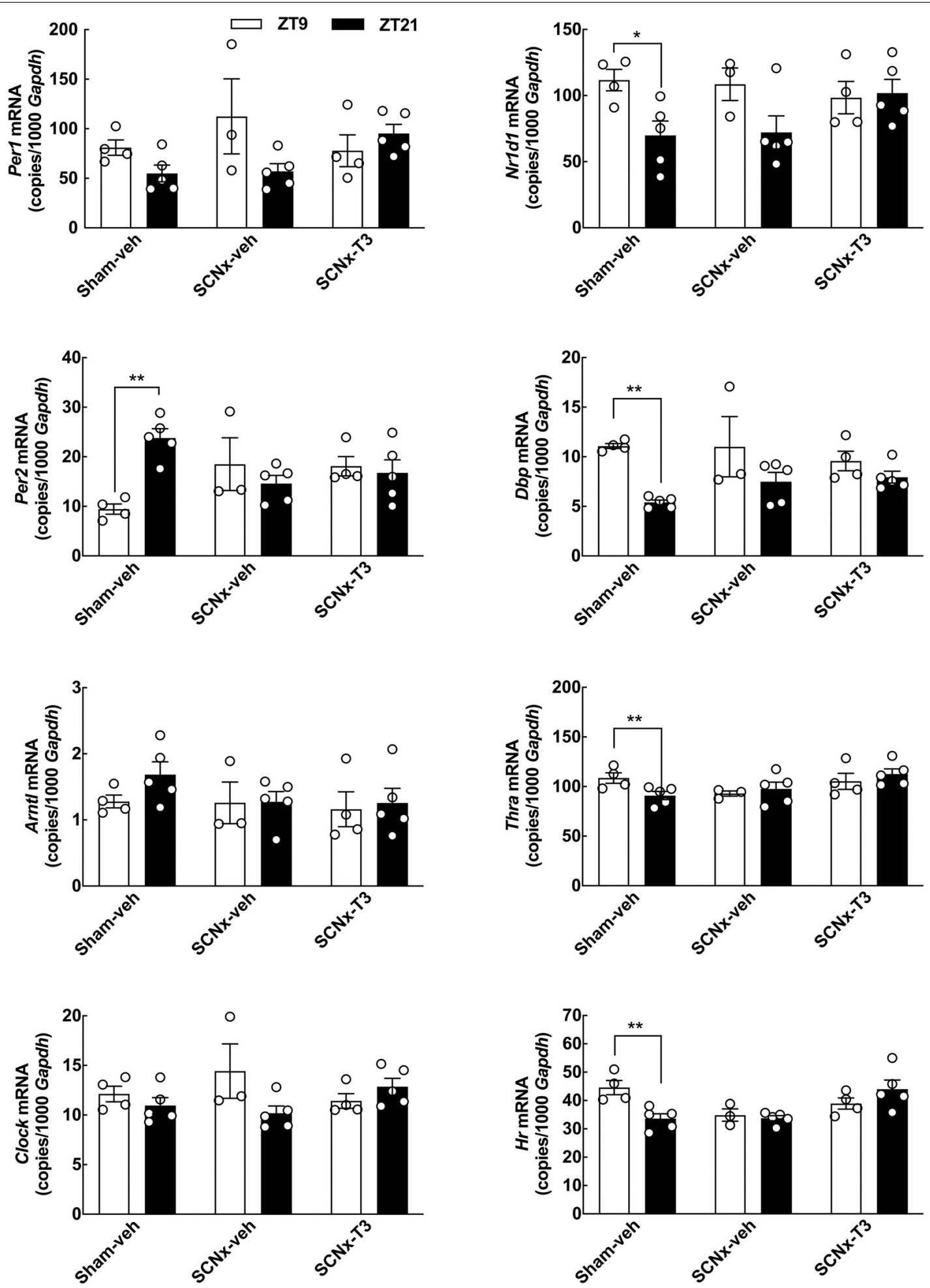

FIGURE 5 | Effects of circadian oscillating T3 concentrations on clock gene expression determined by qRT-PCR. Cerebellar expression of the clock genes Per1, Per2, Arntl, Clock, Nr1d1, and Dbp, as well as Thra and Hr, in three experimental groups of adult rats (8 weeks of age), Sham-veh, SCNx-veh, and SCNx-T3, at ZT9, and ZT21, respectively. Quantitative data were analyzed by two-way ANOVA followed by Bonferroni multiple-comparisons tests. Day-night differences were detected in Sham-veh animals in case of the Per2, Nr1d1, Dbp, Thra, and Hr. Significance levels of Bonferroni multiple-comparisons tests are displayed. * $\mathrm{p}<0.05$; ${ }^{\star *} p<0.01 . n=3-5$. 

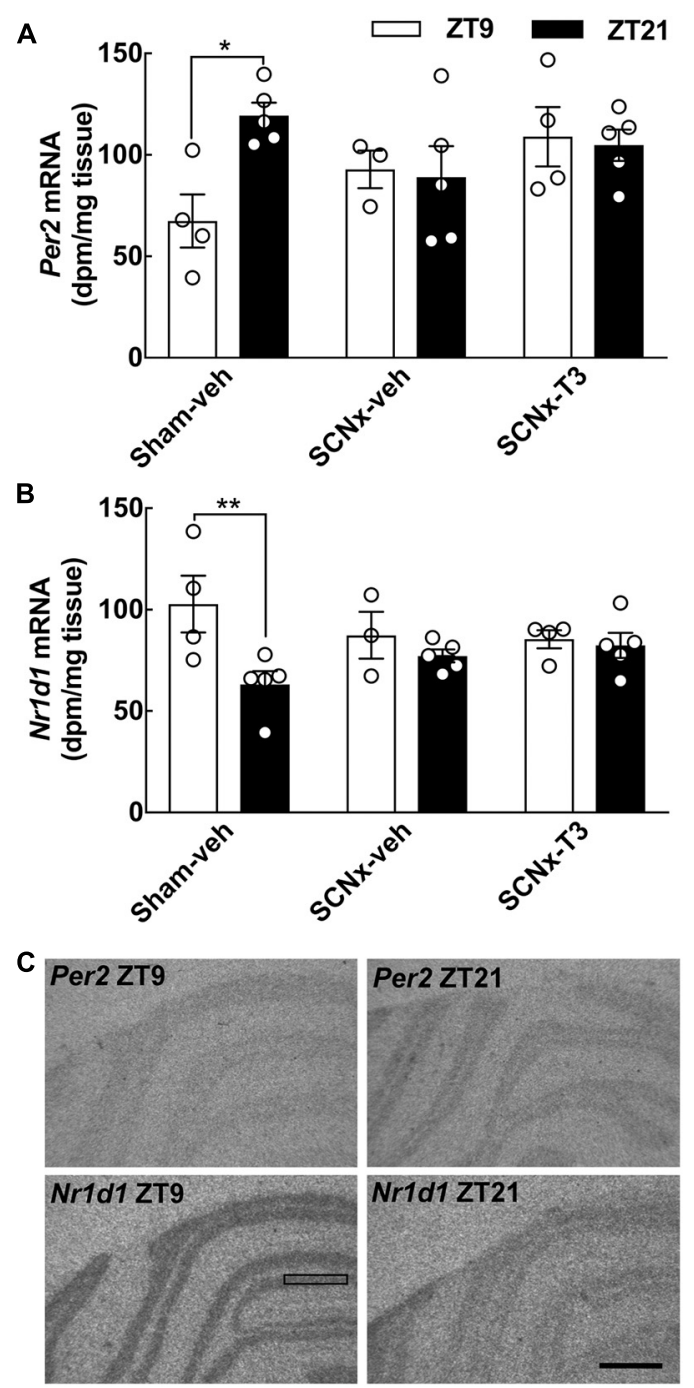

FIGURE 6 | Effects of circadian oscillating T3 concentrations on clock gene expression determined by in situ hybridization. Radiochemical in situ hybridization for detection of the clock gene-encoded transcripts Per2 (A) and Nr1d1 (B) transcripts in the cerebellum of three experimental groups of adult rats (8 weeks of age), Sham-veh, SCNx-veh, and SCNx-T3, at ZT9, and ZT21, respectively. Representative autoradiographs are displayed (C). The rectangle indicates an area of the cerebellar cortex used for quantification. Scale bar, $1 \mathrm{~mm}$. Quantitative data were analyzed by two-way ANOVA followed by Bonferroni multiple-comparisons tests. Day-night differences were detected in Sham-veh animals. Significance levels of Bonferroni multiple-comparisons tests are displayed. ${ }^{*} p<0.05$; ${ }^{* \star} p<0.01 . n=3-5$.

Chi-square periodograms at a period length of $1440 \mathrm{~min}$ and in the relative $Q p$-value (Figure 4D). All SCN lesioned animals were arrhythmic in locomotor activity and body temperature irrespective the pump contents; thus, rhythmic T3 administration does not induce a circadian rhythm in these physiological outputs from the circadian system of the brain that would potentially affect gene expression in the cerebellum indirectly.

Clock gene expression levels in the cerebellum were determined with both qRT-PCR (Figure 5) and in situ hybridization (Figure 6) in all experimental groups. In the control group (Sham-veh), expression levels of the examined genes Per2, Nr1d1, and Dbp all exhibited significant differences between ZT9 and ZT21 in accordance with previous findings (Rath et al., 2012). Per2 exhibited highest expression levels at ZT21 (qRT-PCR: $p<0.01$; in situ hybridization: $p<0.05$, Bonferroni multiple-comparisons tests), Nr1d1 mRNA levels were highest at ZT9 (qRT-PCR: $p<0.05$; in situ hybridization: $p<0.01$, Bonferroni multiple-comparisons tests) and Dbp expression levels were highest at ZT9 (qRT-PCR: $p<0.01$, Bonferroni multiple-comparisons test). In SCN lesioned rats, significant differences in cerebellar expression levels between ZT9 and ZT21 were not detected for Per2, Nr1d1, and Dbp neither in vehicle infused nor in T3 infused rats (Figures 5, 6), suggesting that rhythmic T3 does not restore the daily rhythm in cerebellar clock gene expression. The clock genes that did not exhibit differences in expression between ZT9 and ZT21 were not affected by rhythmic T3 infusion, neither were Thra and $\mathrm{Hr}$ (Figure 5).

\section{Acute in vivo Effects on Clock Gene Expression in the Neonatal Cerebellum From of a Single Triiodothyronine Injection}

The apparent discrepancy between the alterations in clock gene expression induced by $\mathrm{T} 3$ in vitro and our in vivo data in mature rats, as well as the previously reported age-related differences in thyroid responsiveness of cerebellar gene expression (Koibuchi and Chin, 2000), prompted us to investigate the effects of T3 on clock gene expression in the cerebellum of neonatal rats in vivo (Figure 7). IP injections of a high dose of T3 were performed at ZT5 and the rats were subsequently euthanized at ZT9 and ZT17, respectively. qRT-PCR analyses of whole cerebella, showed a significant reduction in Per1 and Per2 transcripts at ZT9 ( $p<0.01$, Bonferroni multiple-comparisons tests). Elevated transcript levels were detected for Nr1d1 at ZT9 $(p<0.001$, Bonferroni multiple-comparisons test) and Dbp at both ZT9 and ZT17 ( $p<0.01$, Bonferroni multiple-comparisons tests) as compared to controls. T3 had no effect on expression of Arntl, Clock, and Thra; however, in contrast to our findings in adult rats (Figure 3), injections of T3 in neonatal rats lead to an increase in expression of $\mathrm{Hr}$ (Figure 7). Thus, T3 modulates the molecular circadian clock of the cerebellum in vivo in neonatal rats.

\section{Diurnal Profile of Clock Gene Expression in the Cerebellum Changes During Development}

The difference in the effect of $\mathrm{T} 3$ on cerebellar clock gene expression at different ages prompted us to investigate the diurnal profiles of expression of clock genes, Thra and $\mathrm{Hr}$ in the cerebellum of neonatal and adult rats (Figure 8). Circadian rhythmic clock gene expression has previously been shown in the cerebellum of the adult rat (Rath et al., 2012), and expectedly, we here found differential expression of the clock genes Per1, Per2, Arntl, Clock, Nr1d1, and Dpb throughout the day-night cycle $(p<0.001$, Bonferroni multiple-comparisons tests), whereas significant daily changes in the neonatal cerebellum were only 

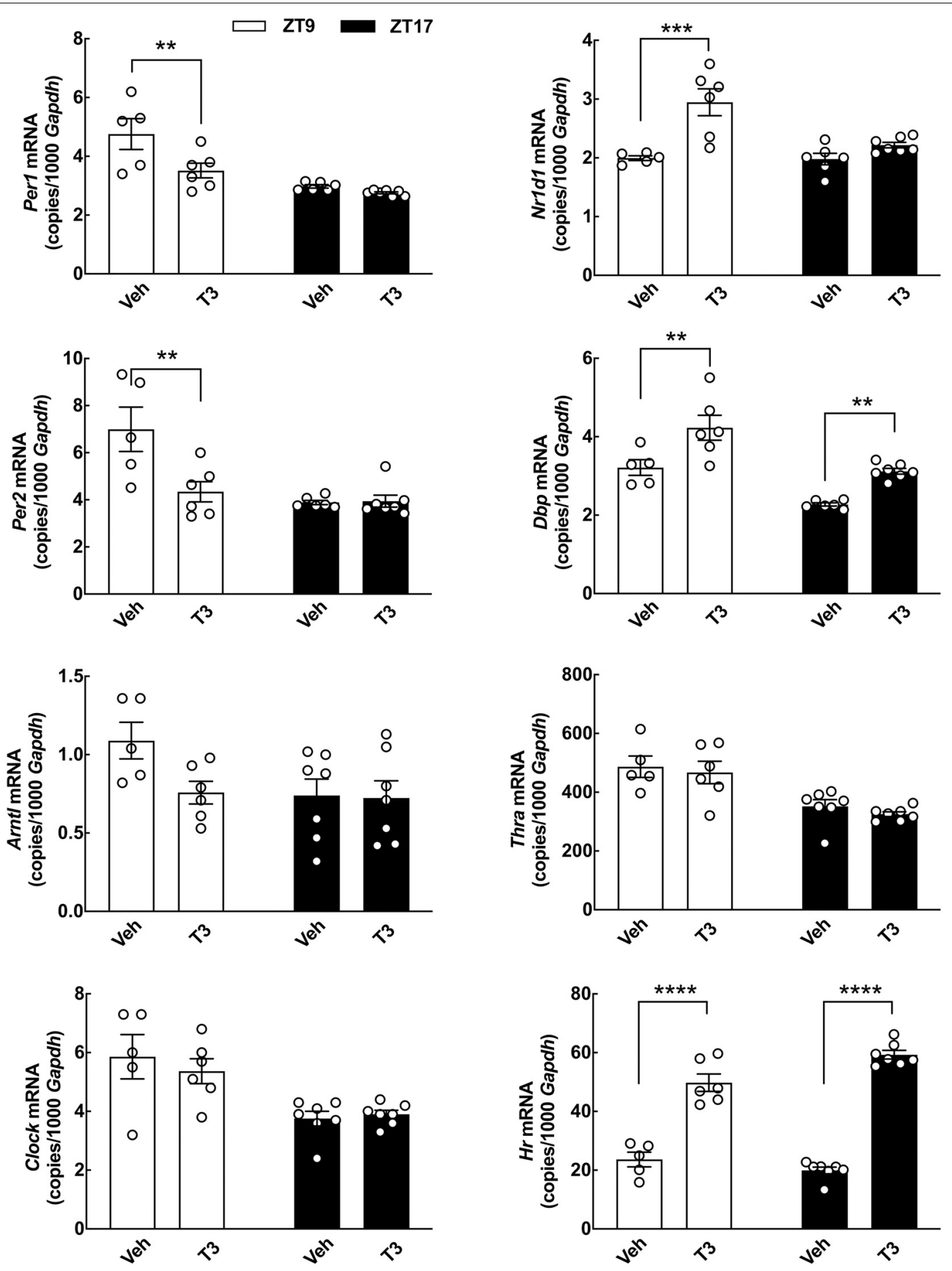

FIGURE 7 | Acute effects of T3 on cerebellar clock gene expression in neonatal rats determined by qRT-PCR. Rat pups (postnatal day 7 ) received 0.1 mg/kg T3 by IP injection at ZT5 and were subsequently euthanized at ZT9 or ZT17. Littermate controls received vehicle (Veh). Quantitative data were analyzed by two-way ANOVA followed by Bonferroni multiple-comparisons tests. Significance levels of Bonferroni multiple-comparisons tests are displayed. ${ }^{\star \star} p<0.01$; ${ }^{\star \star \star} p<0.001$; ${ }^{* * * *} p<0.0001 . n=5-7$.

detectable in case of Arntl ( $p<0.05$, Bonferroni multiplecomparisons test). The expression profile of all clock genes analyzed apart from Arntl differed significantly between ages with higher levels detected in the adult cerebella as compared to the neonatal ( $p<0.001$, two-way ANOVA analyses), suggesting that the circadian oscillator is not fully developed in the neonatal cerebellum. Thra expression was reduced in the adult cerebellum as compared to the neonatal ( $p<0.0001$, two-way ANOVA), 

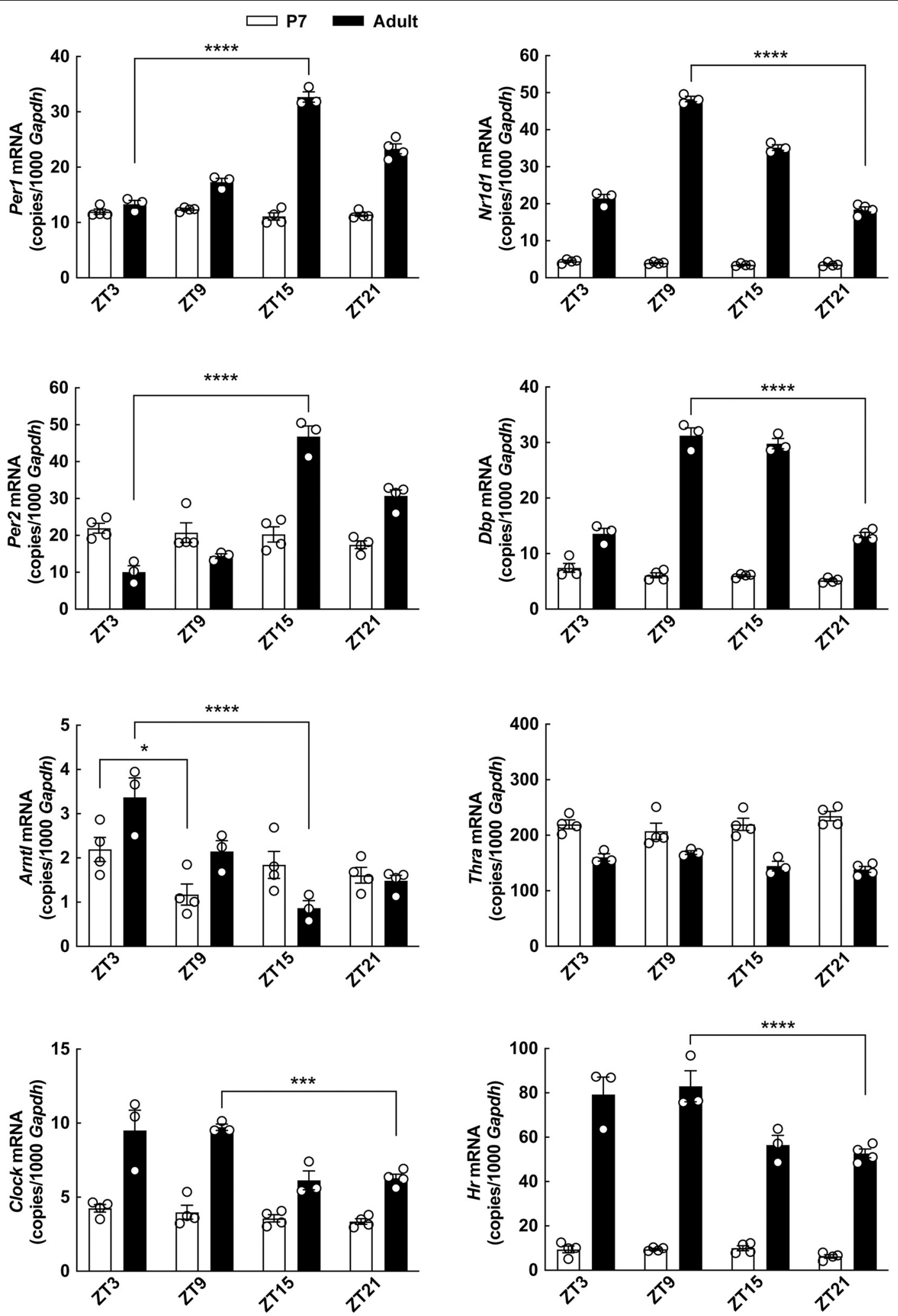

FIGURE 8 | Diurnal profile of clock gene expression in the cerebellum of neonatal and adult rats determined by qRT-PCR. Rat pups (postnatal day 7) and adult rats (8 weeks of age) were kept under a $12 \mathrm{~h}$ light/12 h dark schedule and killed in 6-h intervals. Quantitative data were analyzed by two-way ANOVA followed by Bonferroni multiple-comparisons tests. Only significance levels of Bonferroni multiple-comparisons tests comparing the highest to the lowest expression level of each gene are displayed. ${ }^{\star} p<0.05 ;{ }^{* \star *} p<0.001 ;{ }^{* \star \star \star} p<0.0001 . n=3-4$. 
whereas $\mathrm{Hr}$ was significantly increased in the adult cerebellum ( $p<0.0001$, two-way ANOVA), as indicated by previous northern blot studies (Bradley et al., 1992).

\section{DISCUSSION}

The cerebellar cortex has a documented SCN-dependent circadian clock gene expression profile (Rath et al., 2012), but with no traceable neural afferents from the central pacemaker in the SCN, the only known regulatory circadian signal linking the SCN to the cerebellum is rhythmic release of glucocorticoids from the adrenal glands (Bering et al., 2020). This proves the concept that crosstalk between the endocrine system and the nervous systems drives extra-hypothalamic circadian oscillators. However, in the absence glucocorticoids, rhythmic clock gene expression is still detectable in the cerebellum (Bering et al., 2020), thus prompting us to evaluate the role of another endocrine signal, i.e., T3, in regulation of a circadian brain oscillator. We here provide evidence that T3 modulates circadian clock gene expression in cerebellar granule cells of neonatal rats, but that this hormone loses its effect on the circadian clock-work of the cerebellum during development.

The present study was undertaken to determine if T3 could act as a messenger regulating the local circadian oscillator of the cerebellum. In neonatal rats and in cultured cerebellar granule cells, T3 was capable of modulating transcript levels of the clock genes Per2, Nr1d1, and Dbp, and under certain conditions Per1 and Arntl. The in vitro data suggest a direct effect of T3 on granule cells at the cellular level, whereas apparent genespecific discrepancies between individual transcripts seem to reflect variations in experimental setup and circadian profiles of individual clock genes. The immediate effects on clock gene expression in our in vitro experiments and in vivo experiments in neonatal rats, as opposed to the negative results obtained in adult rats, indicate a higher sensitivity to thyroid hormone in the developing neonate rat brain from which the cell cultures are were also prepared. This interpretation is supported by our analyses of the T3-responsive gene $\mathrm{Hr}$ (Bradley et al., 1992), which was upregulated in response to T3 in the neonatal cerebellum, whereas no effect was seen in any of our experiments performed in adult rats.

Tissues that exhibit circadian oscillations in clock genes in vivo will generally lose their intercellular synchrony when explanted as primary cell cultures (Nagoshi et al., 2004; Welsh et al., 2004). Serum shock can reinstall simultaneous rhythmic oscillations in clock gene transcription in culture (Balsalobre et al., 1998; Kaeffer and Pardini, 2005); this effect has been ascribed to glucocorticoids and both in vitro and in vivo studies support this conclusion (Balsalobre et al., 2000). But as shown here, another hormonal factor, i.e., T3, can exert a similar effect. From a physiological point of view, a reasonable feature in a potential distributor of a central circadian signal must be under a solid $24 \mathrm{~h}$ rhythmic profile. While serum corticosterone exhibits a strong circadian rhythm (Kalsbeek et al., 2012), circadian oscillations in serum T3 have been questioned with discrepancies between studies, suggestively reflecting differences in gender, as well as marked intra- and inter-individual variation (Rookh et al., 1979; Jordan et al., 1980; Campos-Barros et al., 1997; Soutto et al., 1998; Kalsbeek et al., 2000; Fahrenkrug et al., 2017). However, these previous data and the serum T3 measurements reported here do not rule out the possibility that this hormone may act as a costimulatory modulatory component in regulation of extrahypothalamic circadian clocks. A costimulatory effect of T3 in circadian signaling has been documented in a study on mRNA expression of the circadian expression of the controlled dopamine receptor D4 gene (Drd4) in the rat pineal gland (Kim et al., 2010). Similarly, single injections of T3 have been reported to increase expression of otherwise circadian Drd4 in the rat retina (Klitten et al., 2008).

In our initial in vivo T3 experiment on adult rats, we tested the effects of a single high dose T3 injection on clock gene expression, with time points and dose to match previous experiments (Klitten et al., 2008; Kim et al., 2010). Unlike our in vitro results, we did not find any in vivo effects on clock gene transcript levels following injection of $\mathrm{T} 3$ in adult rats. With the considerable sample size chosen for this experiment, it is reasonable to conclude that any immediate effects on cerebellar clock gene expression would have been detected.

Our experimental setup for testing the in vivo effects of T3 infused in a circadian manner was confirmed by combining analyses of telemetry, histology and serum samples; we were able to induce a significant rise in serum T3 at ZT9 by oscillating pump infusion rates in the rats with confirmed arrhythmicity in both daily locomotor activity and body temperature and complete ablation of the SCN. Since intravenous injections of T3 results in a rapid increase of nuclear $\mathrm{T} 3$ in the rat cerebellum (Crantz et al., 1982; Dratman et al., 1991), it is reasonable to expect that oscillations in serum T3 are converted into local oscillations in the cerebellum. On the other hand, we were not able to detect a significant difference in serum T3 in neither the matching vehicle group nor the sham animals with an intact SCN, although we had chosen female rats in our study design to take advantage of the previously reported amplitude in T3 serum concentration oscillations in females (Kalsbeek et al., 2000). As mentioned in the introduction, previous studies have demonstrated conflicting information regarding a potential circadian rhythm in T3 serum levels (van der Heide and EndeVisser, 1980; Waner and Nyska, 1988), and our data do not support a profile with day-night differences.

Thyroid hormones are secreted by the thyroid gland primarily as the inactive T4. Within the brain, a conversion to the active T3 is primarily done by the enzyme deiodinase 2. A high concentration of this enzyme has been found in subregions of the hypothalamus (Tu et al., 1997), but it is detectable in several brain structures including the frontal cortex, hippocampus and cerebellum (Riskind et al., 1987) with a 24 h rhythm documented in the cerebellum (Campos-Barros et al., 1997; Hosoi et al., 1999; Kamiya et al., 1999; Bianco et al., 2002). Cerebellar nuclear T3 was shown to consist of 50-60\% locally converted T3 from T4 (Crantz et al., 1982). In addition, circadian rhythms of T3 in brain tissue have been reported (Campos-Barros et al., 1997); thus, even if the circadian nature of circulating T3 is questionable and may be further complicated by compensatory feedback mechanisms 
(van Doorn et al., 1983), local hormone rhythms within the brain could still exist.

Our gene expression analyses performed using cerebellar tissue from adult rats with infusion pumps confirmed rhythmic clock gene expression in the cerebellum in accord with previous observations (Rath et al., 2012); also, SCN-lesions abolished differential clock gene expression in the cerebellum (Rath et al., 2012; Bering et al., 2020). Although we were clearly able to create a significant timely difference in T3 delivery as measured by serum concentrations, this infusion protocol did not induce daynight differences in any of the analyzed clock genes. As T3 did not influence the transcription of the clock genes in either of the two in vivo studies on adult rats, a role of thyroid hormone in targeting the circadian clock by receptor mediated transcriptional regulation in the mature cerebellum seems unlikely. These findings combined with the absence of a solid circadian hormone profile seem to exclude T3 from being a major circadian inducer of the cerebellar circadian oscillator.

Our developmental findings suggest that T3 influences clock gene expression at a stage where the rhythmic circadian oscillator is not yet present. Since the expression levels of the thyroid hormone receptor Thra are only slightly reduced in the adult cerebellum as compared to neonatal cerebellum, the lacking effect of T3 on cerebellar gene expression in the adult is striking and it does not seem to be limited to clock genes, as none of our studies on the adult cerebellum resulted in an effect of T3 on the otherwise T3-responsive gene $\mathrm{Hr}$. The apparent conflict between our data on neonatal and adult cerebella seems to be due to an age-related mechanism, which involves other changes than the expression of the hormone receptor itself. A critical period around birth, in which genes related to cerebellar development are thyroid responsive, has been identified (Koibuchi and Chin, 2000). Since we see a clear effect of thyroid hormone on clock gene expression in granule cell cultures originating from rat pups and in pups themselves, regulation of clock gene expression by thyroid hormone seems to be possible in the aforementioned window of postnatal sensitivity to thyroid hormone. The circadian clock has been tightly linked to the cell cycle (Feillet et al., 2014; Chaix et al., 2016). Although thyroid hormone does not contribute to the timing of clock gene expression profile in the cerebellum in adult rats, it may influence cerebellar developmental processes via interaction with circadian clock components in the neonatal cerebellum, in which solid

\section{REFERENCES}

Angley, M. T., Sansom, L. N., Smeaton, T. C., and Stupans, I. (1996). The effects of cyclophosphamide on the pharmacokinetics of triiodothyronine in the male rat. J. Pharm. Pharmacol. 48, 386-389. doi: 10.1111/j.2042-7158.1996.tb05938.x

Balsalobre, A., Brown, S. A., Marcacci, L., Tronche, F., Kellendonk, C., Reichardt, H. M., et al. (2000). Resetting of circadian time in peripheral tissues by glucocorticoid signaling. Science 289, 2344-2347. doi: 10.1126/science.289. 5488.2344

Balsalobre, A., Damiola, F., and Schibler, U. (1998). A serum shock induces circadian gene expression in mammalian tissue culture cells. Cell 93, 929-937. doi: 10.1016/S0092-8674(00)81199-X

Bering, T., Carstensen, M. B., and Rath, M. F. (2017). Deleting the Arntl clock gene in the granular layer of the mouse cerebellum: impact on the rhythmic clock gene expression, as we show here, has not been fully developed.

\section{DATA AVAILABILITY STATEMENT}

The raw data supporting the conclusions of this article will be made available by the authors, without undue reservation.

\section{ETHICS STATEMENT}

The animal study was reviewed and approved by the Danish Council for Animal Experiments (authorization number 201715-0201-01190) and by The Faculty of Health and Medical Sciences at University of Copenhagen (authorization numbers P17-311 and P19-118).

\section{AUTHOR CONTRIBUTIONS}

MR conceived the study. TB and MR designed the experiments and wrote the manuscript. $\mathrm{TB}, \mathrm{HH}$, and $\mathrm{MR}$ performed the experiments and analyzed the data. $\mathrm{HH}$ revised the manuscript. All authors approved the final manuscript.

\section{FUNDING}

This study was supported by the Novo Nordisk Foundation (Grant No. NNF17OC0026938 to MR), the Lundbeck Foundation (Grant No. R344-2020-261 to MR) and the Carlsberg Foundation (Grant No. CF17-0070 to MR).

\section{ACKNOWLEDGMENTS}

We wish to thank Rikke Lundorf, BMLT, University of Copenhagen, for excellent technical laboratory services, Profs. Jens Hannibal and Jan Fahrenkrug, Bispebjerg Hospital, for analyzing serum samples and Dr. Stanislava Pankratova, University of Copenhagen, for support in preparation of cerebellar granule cell cultures.

molecular circadian clockwork. J. Neurochem. 142, 841-856. doi: 10.1111/jnc. 14128

Bering, T., Hertz, H., and Rath, M. F. (2020). Rhythmic release of corticosterone induces circadian clock gene expression in the cerebellum. Neuroendocrinology 110, 604-615. doi: 10.1159/000503720

Bianco, A. C., Salvatore, D., Gereben, B., Berry, M. J., and Larsen, P. R. (2002). Biochemistry, cellular and molecular biology, and physiological roles of the iodothyronine selenodeiodinases. Endocr. Rev. 23, 38-89. doi: 10.1210/edrv. 23.1.0455

Bradley, D. J., Towle, H. C., and Young, W. S. III (1992). Spatial and temporal expression of alpha- and beta-thyroid hormone receptor mRNAs, including the beta 2-subtype, in the developing mammalian nervous system. J. Neurosci. 12, 2288-2302. doi: 10.1523/JNEUROSCI.12-06-02288. 1992 
Campos-Barros, A., Musa, A., Flechner, A., Hessenius, C., Gaio, U., Meinhold, H., et al. (1997). Evidence for circadian variations of thyroid hormone concentrations and type II 5'-iodothyronine deiodinase activity in the rat central nervous system. J. Neurochem. 68, 795-803. doi: 10.1046/j.1471-4159. 1997.68020795.x

Chaix, A., Zarrinpar, A., and Panda, S. (2016). The circadian coordination of cell biology. J. Cell Biol. 215, 15-25. doi: 10.1083/jcb.201603076

Challet, E. (2015). Keeping circadian time with hormones. Diabetes Obes. Metab. 17, 76-83. doi: 10.1111/dom.12516

Chatonnet, F., Picou, F., Fauquier, T., and Flamant, F. (2011). Thyroid hormone action in cerebellum and cerebral cortex development. J. Thyroid Res. 2011:145762. doi: 10.4061/2011/145762

Crantz, F. R., Silva, J. E., and Larsen, P. R. (1982). An analysis of the sources and quantity of 3,5,3'-triiodothyronine specifically bound to nuclear receptors in rat cerebral cortex and cerebellum. Endocrinology 110, 367-375. doi: 10.1210/ endo-110-2-367

Dratman, M. B., Crutchfield, F. L., and Schoenhoff, M. B. (1991). Transport of iodothyronines from bloodstream to brain: contributions by blood:brain and choroid plexus:cerebrospinal fluid barriers. Brain Res. 554, 229-236. doi: 10. 1016/0006-8993(91)90194-Z

Fahrenkrug, J., Georg, B., Hannibal, J., and Jorgensen, H. L. (2017). Hypophysectomy abolishes rhythms in rat thyroid hormones but not in the thyroid clock. J. Endocrinol. 233, 209-216. doi: 10.1530/JOE-170111

Feillet, C., Krusche, P., Tamanini, F., Janssens, R. C., Downey, M. J., Martin, P., et al. (2014). Phase locking and multiple oscillating attractors for the coupled mammalian clock and cell cycle. Proc. Natl. Acad. Sci. USA 111, 9828-9833. doi: 10.1073/pnas.1320474111

Giannocco, G., DosSantos, R. A., and Nunes, M. T. (2004). Thyroid hormone stimulates myoglobin gene expression in rat cardiac muscle. Mol. Cell Endocrinol. 226, 19-26. doi: 10.1016/j.mce.2004.07.007

Hernandez-Linares, Y., Olvera, A., Villalobos, P., Lozano-Flores, C., VarelaEchavarria, A., Luna, M., et al. (2019). 3,5-T2 and 3,3'5-T3 Regulate cerebellar thyroid hormone signalling and myelin molecular dynamics in tilapia. Sci. Rep. 9:7359. doi: 10.1038/s41598-019-43701-w

Hosoi, Y., Murakami, M., Mizuma, H., Ogiwara, T., Imamura, M., and Mori, M. (1999). Expression and regulation of type II iodothyronine deiodinase in cultured human skeletal muscle cells. J. Clin. Endocrinol. Metab. 84, 3293-3300. doi: 10.1210/jc.84.9.3293

Ilieva, M., Nielsen, J., Korshunova, I., Gotfryd, K., Bock, E., Pankratova, S., et al. (2019). Artemin and an artemin-derived peptide, artefin, induce neuronal survival, and differentiation through ret and NCAM. Front. Mol. Neurosci. 12:47. doi: 10.3389/fnmol.2019.00047

Jordan, D., Rousset, B., Perrin, F., Fournier, M., and Orgiazzi, J. (1980). Evidence for circadian variations in serum thyrotropin, 3,5,3'-triiodothyronine, and thyroxine in the rat. Endocrinology 107, 1245-1248. doi: 10.1210/endo-1074- 1245

Kaeffer, B., and Pardini, L. (2005). Clock genes of Mammalian cells: practical implications in tissue culture. Vitro. Cell Dev. Biol. Anim. 41, 311-320. doi: 10.1007/s11626-005-0001-7

Kalsbeek, A., and Fliers, E. (2013). Daily regulation of hormone profiles. Handb. Exp. Pharmacol. 2013, 185-226. doi: 10.1007/978-3-642-25950-0_8

Kalsbeek, A., Fliers, E., Franke, A. N., Wortel, J., and Buijs, R. M. (2000). Functional connections between the suprachiasmatic nucleus and the thyroid gland as revealed by lesioning and viral tracing techniques in the rat. Endocrinology 141, 3832-3841. doi: 10.1210/endo.141.10.7709

Kalsbeek, A., van der Spek, R., Lei, J., Endert, E., Buijs, R. M., and Fliers, E. (2012). Circadian rhythms in the hypothalamo-pituitary-adrenal (HPA) axis. Mol. Cell Endocrinol. 349, 20-29. doi: 10.1016/j.mce.2011.06.042

Kamiya, Y., Murakami, M., Araki, O., Hosoi, Y., Ogiwara, T., Mizuma, H., et al. (1999). Pretranslational regulation of rhythmic type II iodothyronine deiodinase expression by beta-adrenergic mechanism in the rat pineal gland. Endocrinology 140, 1272-1278. doi: 10.1210/endo.140.3.6594

Kim, J. S., Bailey, M. J., Weller, J. L., Sugden, D., Rath, M. F., Moller, M., et al. (2010). Thyroid hormone and adrenergic signaling interact to control pineal expression of the dopamine receptor D4 gene (Drd4). Mol. Cell Endocrinol. 314, 128-135. doi: 10.1016/j.mce.2009.05.013
Klitten, L. L., Rath, M. F., Coon, S. L., Kim, J. S., Klein, D. C., and Moller, M. (2008). Localization and regulation of dopamine receptor D4 expression in the adult and developing rat retina. Exp. Eye Res. 87, 471-477. doi: 10.1016/j.exer.2008. 08.004

Ko, C. H., and Takahashi, J. S. (2006). Molecular components of the mammalian circadian clock. Hum. Mol. Genet. 15:R271. doi: 10.1093/hmg/ddl207

Koibuchi, N., and Chin, W. W. (2000). Thyroid hormone action and brain development. Trends Endocrinol. Metab. 11, 123-128. doi: 10.1016/S10432760(00)00238-1

Legrand, J. (1979). Morphogenetic Actions of Thyroid-Hormones. Trends Neurosci. 2, 234-236. doi: 10.1016/0166-2236(79)90091-2

Mendoza, J., Pevet, P., Felder-Schmittbuhl, M. P., Bailly, Y., and Challet, E. (2010). The cerebellum harbors a circadian oscillator involved in food anticipation. J. Neurosci. 30, 1894-1904. doi: 10.1523/JNEUROSCI.5855-09. 2010

Nagoshi, E., Saini, C., Bauer, C., Laroche, T., Naef, F., and Schibler, U. (2004). Circadian gene expression in individual fibroblasts: cell-autonomous and selfsustained oscillators pass time to daughter cells. Cell 119, 693-705. doi: 10 . 1016/j.cell.2004.11.015

Rath, M. F., Rohde, K., Fahrenkrug, J., and Moller, M. (2013). Circadian clock components in the rat neocortex: daily dynamics, localization and regulation. Brain Struct. Funct. 218, 551-562. doi: 10.1007/s00429-0120415-4

Rath, M. F., Rohde, K., and Moller, M. (2012). Circadian oscillations of molecular clock components in the cerebellar cortex of the rat. Chronobiol. Int. 29, 1289-1299. doi: 10.3109/07420528.2012.728660

Rath, M. F., Rovsing, L., and Moller, M. (2014). Circadian oscillators in the mouse brain: molecular clock components in the neocortex and cerebellar cortex. Cell Tissue Res. 357, 743-755. doi: 10.1007/s00441-014-1878-9

Refinetti, R. (2004). Non-stationary time series and the robustness of circadian rhythms. J. Theor. Biol. 227, 571-581. doi: 10.1016/j.jtbi.2003. 11.032

Remaud, S., Gothie, J. D., Morvan-Dubois, G., and Demeneix, B. A. (2014). Thyroid hormone signaling and adult neurogenesis in mammals. Front. Endocrinol. 5:62. doi: 10.3389/fendo.2014.00062

Reppert, S. M., and Weaver, D. R. (2002). Coordination of circadian timing in mammals. Nature 418, 935-941. doi: 10.1038/nature00965

Riskind, P. N., Kolodny, J. M., and Larsen, P. R. (1987). The regional hypothalamic distribution of type II 5'-monodeiodinase in euthyroid and hypothyroid rats. Brain Res. 420, 194-198. doi: 10.1016/0006-8993(87)90260-5

Rookh, H. V., Azukizawa, M., DiStefano, J. J. III, Ogihara, T., and Hershman, J. M. (1979). Pituitary-thyroid hormone periodicities in serially sampled plasma of unanesthetized rats. Endocrinology 104, 851-856. doi: 10.1210/endo-104$4-851$

Schmid, B., Helfrich-Forster, C., and Yoshii, T. (2011). A new ImageJ plug-in “ActogramJ" for chronobiological analyses. J. Biol. Rhythms 26, 464-467. doi: 10.1177/0748730411414264

Smith, J. W., Evans, A. T., Costall, B., and Smythe, J. W. (2002). Thyroid hormones, brain function and cognition: a brief review. Neurosci. Biobehav. Rev. 26, 45-60. doi: 10.1016/S0149-7634(01)00037-9

Soutto, M., Guerrero, J. M., Osuna, C., and Molinero, P. (1998). Nocturnal increases in the triiodothyronine/thyroxine ratio in the rat thymus and pineal gland follow increases of type II 5'-deiodinase activity. Int. J. Biochem. Cell Biol. 30, 235-241. doi: 10.1016/S1357-2725(97)00116-7

Thompson, C. C. (1996). Thyroid hormone-responsive genes in developing cerebellum include a novel synaptotagmin and a hairless homolog. J. Neurosci. 16, 7832-7840. doi: 10.1523/JNEUROSCI.16-24-07832.1996

Tu, H. M., Kim, S. W., Salvatore, D., Bartha, T., Legradi, G., Larsen, P. R., et al. (1997). Regional distribution of type 2 thyroxine deiodinase messenger ribonucleic acid in rat hypothalamus and pituitary and its regulation by thyroid hormone. Endocrinology 138, 3359-3368. doi: 10.1210/endo.138.8.5318

van der Heide, D., and Ende-Visser, M. P. (1980). T4, T3 and reverse T3 in the plasma of rats during the first 3 months of life. Acta Endocrinol. 93, 448-454. doi: 10.1530/acta.0.0930448

van Doorn, J., van der Heide, D., and Roelfsema, F. (1983). Sources and quantity of 3,5,3'-triiodothyronine in several tissues of the rat. J. Clin. Invest. 72, 1778-1792. doi: 10.1172/JCI111138 
Vrang, N., Larsen, P. J., Moller, M., and Mikkelsen, J. D. (1995). Topographical organization of the rat suprachiasmatic-paraventricular projection. J. Comp. Neurol. 353, 585-603. doi: 10.1002/cne.903530409

Vrang, N., Mikkelsen, J. D., and Larsen, P. J. (1997). Direct link from the suprachiasmatic nucleus to hypothalamic neurons projecting to the spinal cord: a combined tracing study using cholera toxin subunit $B$ and Phaseolus vulgarisleucoagglutinin. Brain Res. Bull. 44, 671-680. doi: 10.1016/S0361-9230(97) 00138-X

Waner, T., and Nyska, A. (1988). Thyroxine (T4) and triiodothyronine (T3) levels in the Fischer 344 inbred rat. Lab. Anim. 22, 276-280. doi: 10.1258/ 002367788780746458

Welsh, D. K., Yoo, S. H., Liu, A. C., Takahashi, J. S., and Kay, S. A. (2004). Bioluminescence imaging of individual fibroblasts reveals persistent, independently phased circadian rhythms of clock gene expression. Curr. Biol. 14, 2289-2295. doi: 10.1016/j.cub.2004. 11.057
Conflict of Interest: The authors declare that the research was conducted in the absence of any commercial or financial relationships that could be construed as a potential conflict of interest.

Publisher's Note: All claims expressed in this article are solely those of the authors and do not necessarily represent those of their affiliated organizations, or those of the publisher, the editors and the reviewers. Any product that may be evaluated in this article, or claim that may be made by its manufacturer, is not guaranteed or endorsed by the publisher.

Copyright $\odot 2021$ Bering, Hertz and Rath. This is an open-access article distributed under the terms of the Creative Commons Attribution License (CC BY). The use, distribution or reproduction in other forums is permitted, provided the original author(s) and the copyright owner(s) are credited and that the original publication in this journal is cited, in accordance with accepted academic practice. No use, distribution or reproduction is permitted which does not comply with these terms. 